\title{
Efficacy and tolerability of adjunctive perampanel treatment in children under 12 years of age with refractory epilepsy
}

\author{
Yuni Yun, MD', Dongsub Kim, MD², Yun-Jeong Lee, MD', Soonhak Kwon, MD', Su-Kyeong Hwang, MD, PhD' \\ ${ }^{1}$ Department of Pediatrics, School of Medicine, Kyungpook National University, Daegu, ${ }^{2}$ Department of Pediatrics, Samsung Medical Center, Sungkyunkwan \\ University School of Medicine, Seoul, Korea
}

Purpose: There is limited data on the use of perampanel in children under 12 years of age. We evaluated the efficacy and tolerability of adjunctive perampanel treatment in children under 12 years of age with refractory epilepsy.

Methods: This retrospective observational study was performed in Kyungpook National University Hospital from July 2016 to March 2018. A responder was defined as a patient with $\geq 50 \%$ reduction in monthly seizure frequency compared with the baseline. Adverse events and discontinuation data were obtained to evaluate tolerability.

Results: Twenty-two patients (8 males, 14 females) aged 3.1-11.4 years (mean, 8.0 2.5 years) were included in this study. After an average of 9.2 months (range, 0.5-19 months) of follow-up, 15 patients $(68 \%)$ showed a reduction in seizure frequency, including 5 patients (23\%) with seizure freedom. The age at epilepsy onset was significantly lower $(P=0.048)$, and the duration of epilepsy was significantly longer $(P=0.019)$ in responders than in nonresponders. Nine patients $(41 \%)$ experienced adverse events, including somnolence (23\%), respiratory depression (9\%), violence (4.5\%), and seizure aggravation (4.5\%). The most serious adverse event was respiratory depression, which required mechanical ventilation in 2 patients (9\%). Eight patients (36\%) discontinued perampanel due to lack of efficacy or adverse events. Three out of 4 patients (75\%) who discontinued perampanel due to adverse events had an underlying medical condition.

Conclusion: Perampanel offers a treatment option for refractory epilepsy in children. Adjunctive treatment with perampanel requires special consideration in those with underlying medical conditions to prevent serious adverse events.

Key words: Perampanel, Child, Efficacy, Tolerability, Adverse events

\section{Introduction}

Over the past 20 years, more than a dozen new antiepileptic drugs (AEDs) with different mechanisms of action have been developed. Yet these drugs have not led to a substantial improvement in patients with medically refractory epilepsy. ${ }^{1,2)}$

Therefore, pharmacoresistant patients require AEDs with novel mechanisms of action. ${ }^{3)}$ Perampanel, one of the latest AEDs, is the first $\alpha$-amino-3-hydroxy-5-methyl-4-isoxazolepropionic acid (AMPA) receptor antagonist. ${ }^{4)}$ Perampanel inhibits AMPA-induced increases in intracellular $\mathrm{Ca}^{2+}$ and selectively blocks AMPA receptor-mediated synaptic transmission, thus reducing neuronal excitation. ${ }^{5)}$ Perampanel is primarily metabolized by CYP3A4 of the P450 enzyme system, and enzyme-inducing drugs such as carbamazepine, oxcarbazepine, and phenytoin significantly increase the clearance of perampanel and decrease its plasma
Corresponding author: Su-Kyeong Hwang, MD, $\mathrm{PhD}$

Department of Pediatrics, School of Medicine, Kyungpook National University, Hogook-Ro 807, Book-Gu, Daegu 41404, Korea

Tel: +82-53-200-5704

Fax: +82-53-425-6683

E-mail: skhwang@knu.ac.kr

https://orcid.org/0000-0001-8294-7094

Received: 14 August, 2018

Revised: 21 December, 2018

Accepted: 26 December, 2018

Copyright @ 2019 by The Korean Pediatric Society

This is an open-access article distributed under the terms of the Creative Commons Attribution NonCommercial License (http://creativecommons.org/ licenses/by-nc/4.0/n which permits unrestricted noncommercial use, distribution, and reproduction in any medium, provided the original work is properly cited. 
concentration. $^{3,6)}$

In patients aged 12 years and older, perampanel is approved for partial-onset seizures with or without secondary generalization, and for primary generalized tonic-clonic seizures. ${ }^{7,8)}$ Although the adjunctive therapy of perampanel for refractory epilepsy is well established, there is limited data on the use of perampanel in children under 12 years of age, and there are no studies on the use of perampanel involving only children younger than 12 years of age. To evaluate the efficacy and tolerability of perampanel in children under 12 years of age with epilepsy, we performed a retrospective study.

\section{Materials and methods}

This retrospective observational study was performed in Kyungpook National University Hospital from July 2016 to March 2018. Medical records from 22 children younger than 12 years of age with various types of epilepsy who had add-on perampanel treatment were reviewed. The Institutional Review Board (IRB) approved the protocol (KNUH-IRB-2018-08-034) and informed consent was waived because of the retrospective nature of the study.

The data collected included the following: sex, age when starting perampanel, age at epilepsy onset, duration of epilepsy, seizure types, etiology, number of concomitant AEDs, concomitant enzymeinducing AEDs, seizure frequency per month. Seizure types were classified as focal, generalized, combined focal and generalized, and unknown. Epilepsy etiologies classified as structural, genetic, infectious, metabolic, immune, and unknown. ${ }^{9)}$ To assess efficacy, mean seizure frequency per month during 3 months before perampanel treatment was obtained. The mean starting dosage was 1.4 $\mathrm{mg} /$ day (range, $0.5-2.0 \mathrm{mg} /$ day) given once in the evening and was increased every 2-4 weeks up to 1 to $12 \mathrm{mg} /$ day (mean, $3.8 \mathrm{mg} /$ day) depending on clinical response and tolerability. The criterion for efficacy was based on the seizure frequency during the observation period, compared with baseline. Response was defined as a $\geq 50 \%$ reduction in monthly seizure frequency; seizure freedom was defined as a $100 \%$ reduction on a final maintenance dose of perampanel for at least 3 months.

Adverse events and discontinuation data were obtained to assess

Table 1. Baseline characteristics of patients $(n=22)$

\begin{tabular}{|c|c|c|c|c|c|c|c|c|c|c|}
\hline $\begin{array}{l}\text { Patient } \\
\text { No. }\end{array}$ & $\begin{array}{l}\text { Age } \\
\text { (yr) }\end{array}$ & Sex & Etiology & $\begin{array}{l}\text { Seizure } \\
\text { type }\end{array}$ & $\begin{array}{l}\text { Age at } \\
\text { epilepsy } \\
\text { onset } \\
\text { (yr) }\end{array}$ & $\begin{array}{l}\text { Duration } \\
\text { of epilepsy } \\
\text { (yr) }\end{array}$ & $\begin{array}{c}\text { Enzyme- } \\
\text { inducing } \\
\text { AEDs }\end{array}$ & $\begin{array}{c}\text { Final } \\
\text { maintenance } \\
\text { dose }(\mathrm{mg}) \text { of } \\
\text { PER }(\mathrm{mg} / \mathrm{kg})\end{array}$ & $\begin{array}{l}\text { Seizure } \\
\text { frequency } \\
\text { reduction } \\
(\%)\end{array}$ & Adverse events \\
\hline 1 & 7.1 & $\mathrm{M}$ & Cerebral dysgenesis & C & 0.1 & 7 & Yes & $4(0.30)$ & 50 & None \\
\hline 2 & 9.7 & $\mathrm{~F}$ & Cystic encephalomalacia & C & 0.1 & 9.6 & Yes & $3(0.18)$ & 50 & None \\
\hline 3 & 10.8 & $\mathrm{M}$ & Traumatic brain injury & G & 10.3 & 5 & Yes & $4(0.13)$ & 50 & None \\
\hline 4 & 8.6 & M & Schizencephaly with absence of septum pellucidum & C & 4.7 & 3.8 & Yes & $4(0.22)$ & 50 & None \\
\hline 5 & 5.9 & $\mathrm{M}$ & Lissencephaly & G & 0.5 & 5.4 & No & $6(0.40)$ & 50 & None \\
\hline 6 & 9.2 & $\mathrm{~F}$ & Rett syndrome & C & 7.2 & 2 & No & $2(0.10)$ & 50 & None \\
\hline 7 & 6.4 & $\mathrm{~F}$ & Idiopathic & C & 4.5 & 1.7 & No & $6(0.13)$ & 50 & None \\
\hline 8 & 6.3 & $\mathrm{~F}$ & Idiopathic & C & 4.3 & 3 & No & $1(0.03)$ & 100 & None \\
\hline 9 & 3.1 & $\mathrm{~F}$ & Posthemorrhagic hydrocephalus & C & 1.8 & 1.3 & No & $2(0.20)$ & 50 & None \\
\hline 10 & 8.7 & $\mathrm{~F}$ & Idiopathic & G & 0.3 & 8.4 & No & $2(0.05)$ & 100 & Somnolence \\
\hline 11 & 9.9 & $\mathrm{~F}$ & Leukoencephalopathy & G & 4.2 & 5.1 & No & $4(0.11)$ & 50 & None \\
\hline 12 & 9.6 & $\mathrm{~F}$ & Idiopathic & $\mathrm{F}$ & 7.7 & 1.9 & No & $5(0.10)$ & 50 & None \\
\hline 13 & 3.2 & $\mathrm{~F}$ & Hypoxic ischemic encephalopathy & C & 0.5 & 2.9 & No & $0.5(0.04)$ & 100 & Respiratory depression \\
\hline 14 & 10.3 & $\mathrm{~F}$ & Lennox-Gastaut syndrome & C & 0.2 & 10.1 & No & $2(0.17)$ & 100 & Respiratory depression \\
\hline 15 & 4.7 & $\mathrm{~F}$ & Cohen syndrome & C & 4.0 & 0.6 & No & $1(0.10)$ & 100 & Violence \\
\hline 16 & 6.9 & $\mathrm{~F}$ & Idiopathic & C & 0.5 & 6.4 & No & $6(0.27)$ & None & Somnolence \\
\hline 17 & 8.4 & $\mathrm{~F}$ & Encephalomalacia due to thromboembolic insult & C & 3.0 & 3.4 & Yes & $4(0.11)$ & None & Somnolence \\
\hline 18 & 11 & M & Idiopathic & G & 3.7 & 7.1 & No & $6(0.13)$ & None & Somnolence \\
\hline 19 & 5.5 & M & ADNFLE & C & 5.4 & 0.1 & Yes & $2(0.10)$ & None & Somnolence \\
\hline 20 & 9.7 & $\mathrm{~F}$ & Idiopathic & $\mathrm{F}$ & 6.1 & 3.6 & No & $2(0.09)$ & None & Seizure aggravation \\
\hline 21 & 10.1 & M & Idiopathic & C & 8.5 & 1.6 & No & $6(0.08)$ & 25 & None \\
\hline 22 & 11.4 & $\mathrm{M}$ & FIRES & G & 7.3 & 4.1 & Yes & $12(0.30)$ & None & None \\
\hline
\end{tabular}

Enzyme-inducing AEDs, antiepileptic drugs that stimulate the synthesis of a broad range of monooxygenase and conjugating enzymes, such as carbamazepine, phenytoin, and oxcarbazepine; PER, perampanel; $G$, generalized; C, combined focal and generalized; F, focal; ADNFLE, autosomal dominant nocturnal frontal lobe epilepsy; FIRES, febrile illness related epilepsy syndrome. 
tolerability. Seizure aggravation was classified as an adverse event. For statistical comparison between responders and nonresponders, the Mann-Whitney test was used for continuous variables and the Fisher exact test was used for categorical variables. Continuous data were presented as means and standard deviations and categorical data as actual numbers and percentages. $P$ values $<0.05$ were considered statistically significant. All analyses were performed using IBM SPSS Statistics ver. 23.0 (IBM Co., Armonk, NY, USA).

\section{Results}

\section{Patient population}

Table 1 shows baseline characteristics of patients. We evaluated 22 patients (8 males, 14 females) aged 3.1 to 11.4 years (mean, $8.0 \pm 2.5$ years). The mean observation period was 9.2 months (range, 0.5-19 months) after the introduction of perampanel. Eight patients (36\%) attributed to a structural cause, 3 patients (14\%) had a genetic etiology, and 11 patients (50\%) had epilepsy of unknown cause. Two patients (9\%) had focal seizures, 7 patients (32\%) had generalized seizures, and 13 patients (59\%) had combined focal and generalized seizures. The mean age at epilepsy onset was $3.9 \pm 3.1$ years and the mean duration of epilepsy before perampanel treatment was $4.3 \pm 2.9$ years. Seven patients (32\%) were on enzyme-inducing AEDs. The mean final maintenance dose of perampanel was $3.8 \pm 2.5 \mathrm{mg}$.

\section{Efficacy}

Table 2 demonstrates comparison of demographics and outcomes between responders and nonresponders. Fifteen patients (68\%), including 5 patients (23\%) with seizure freedom, were responders and 7 patients (32\%) were nonresponders. There was no statistical significance between responders and nonresponders in sex, seizure type, etiology, presence of concomitant enzyme-inducing AEDs, discontinuation rate, age when starting perampanel, duration of perampanel treatment, number of concomitant AEDs, seizure frequency per month, and perampanel dose. Age at epilepsy onset was significantly younger in responders $(P=0.048)$; duration of epilepsy was significantly longer in responders $(P=0.019)$ than in nonresponders.

Table 2. Comparison of demographics and outcomes between responders and nonresponders

\begin{tabular}{|c|c|c|c|c|c|}
\hline \multirow{2}{*}{ Variable } & \multicolumn{2}{|c|}{ Responders ( $n=15)$} & \multicolumn{2}{|c|}{ Nonresponders $(\mathrm{n}=7)$} & \multirow{2}{*}{$P$ value } \\
\hline & Mean \pm SD & Median & Mean $\pm S D$ & Median & \\
\hline Age at epilepsy onset (yr) & $3.4 \pm 3.2$ & 4.0 & $4.9 \pm 2.7$ & 5.4 & $0.048^{*}$ \\
\hline Age when starting PER (yr) & $7.6 \pm 2.5$ & 8.6 & $9.0 \pm 2.2$ & 9.7 & 0.060 \\
\hline Duration of epilepsy (yr) & $4.5 \pm 3.1$ & 3.8 & $3.8 \pm 2.5$ & 3.6 & $0.019^{\star}$ \\
\hline Duration of PER treatment (mo) & $11.8 \pm 7.0$ & 12.5 & $4.1 \pm 4.2$ & 3.0 & 0.225 \\
\hline Number of concomitant AEDs & $2.3 \pm 1.5$ & 2.0 & $2.9 \pm 1.1$ & 3.0 & 0.214 \\
\hline Seizure frequency per month & $27.1 \pm 41.0$ & 4.0 & $60.6 \pm 111.5$ & 3.0 & 0.366 \\
\hline Initial dose per weight (mg/kg) & $0.06 \pm 0.02$ & 0.06 & $0.05 \pm 0.03$ & 0.04 & 0.349 \\
\hline Final dose per weight (mg/kg) & $0.15 \pm 0.10$ & 0.13 & $0.15 \pm 0.09$ & 0.11 & 0.288 \\
\hline Female sex (\%) & 75.0 & & 33.3 & & 0.137 \\
\hline Seizure type (\%) & & & & & 0.249 \\
\hline Generalized & 25.0 & & 50.0 & & \\
\hline Focal & 6.3 & & 16.7 & & \\
\hline Combined & 68.7 & & 33.3 & & \\
\hline Etiology (\%) & & & & & 0.443 \\
\hline Genetic & 12.5 & & 16.7 & & \\
\hline Infection & 0 & & 0 & & \\
\hline Metabolic & 0 & & 0 & & \\
\hline Structural & 43.8 & & 16.7 & & \\
\hline Unknown & 43.8 & & 66.6 & & \\
\hline Patients on enzyme inducing AEDs (\%) & 25 & & 50.0 & & 0.334 \\
\hline Discontinuation (\%) & & & & & 0.333 \\
\hline Due to adverse events & 18.8 & & 83.3 & & \\
\hline Due to lack of efficacy & 18.8 & & 16.7 & & \\
\hline
\end{tabular}




\section{Tolerability}

Nine patients (41\%) experienced adverse events including somnolence (23\%), respiratory depression (9\%), violence (4.5\%), and seizure aggravation (4.5\%). One patient (11\%) had severe somnolence when the patient was taking $4.0 \mathrm{mg}$ of perampanel. Since the reduction of perampanel to $2.0 \mathrm{mg}$, the patient has not displayed any further somnolence. Eight patients (36\%) discontinued perampanel due to lack of efficacy or adverse events. Three out of 4 patients (75\%) who discontinued perampanel due to adverse events had an underlying medical condition: respiratory depression occurred in 2 bedridden patients previously diagnosed with compromised respiratory function; violence occurred in a patient who had attention deficit hyperactivity disorder. One patient in nonresponders had seizure aggravation and discontinued perampanel. The most serious adverse event was respiratory depression which required mechanical ventilation in 2 patients (9\%). All adverse events resolved after discontinuation of perampanel. The mean perampanel dose in those who discontinued perampanel due to adverse events was $1.5 \mathrm{mg}$. Among 7 patients (32\%) who had lack of efficacy, 4 patients (57\%) discontinued perampanel and the mean perampanel dose was $4.0 \mathrm{mg}$.

\section{Discussion}

Adjunctive treatment with perampanel in children under 12 years of age was efficacious and tolerated as in adults. Sixty-eight percent of the patients showed treatment response, and adverse events seen were generally well tolerated. Factors affecting treatment response were younger age at epilepsy onset and longer duration of epilepsy.

In a study on perampanel tolerability and effectiveness in 58 children and adolescents aged 2 to 17 years (mean age, 10.5 years), response rate after the first 3 months was 31\%, which is similar to adult data. ${ }^{10)}$ In a study of 62 children and adolescents aged 6 to 18 year (mean age, 14.2 years) including $13 \%$ of patients aged $<12$ years, response rate was $50 \%$ with that children $\geq 12$ years tended to have a better response (53.7\%) than younger children (25.0\%). ${ }^{11)}$ In another study of 24 children and adolescents treated with perampanel aged 1.5 to 17 years (mean age, 10 year), response rate was $42 \% .{ }^{12)}$ Our patients showed a better response (68\%) compared to the previous studies.

Adverse events were reported in 30.6\%-60.6\% of children and adolescents in previous studies. ${ }^{11,12)}$ Although most adverse events were acceptable and resolved after dose reduction or discontinuation of perampanel, respiratory depression that required mechanical ventilation was potentially life-threatening. Seventy-five percent of those who discontinued perampanel due to adverse events had an underlying medical condition including compromised respiratory function and attention deficit hyperactivity disorder. Thus, adverse events should be carefully monitored along with responses especially in patients with underlying medical conditions.

Factors including sex, seizure type, etiology, presence of concomitant enzyme-inducing AEDs, discontinuation rate, age when starting perampanel, duration of perampanel treatment, number of concomitant AEDs, baseline seizure frequency, and perampanel dose did not significantly affect treatment response in our study. Theoretically, enzyme-inducing AEDs are thought to interfere with the metabolism of perampanel. The majority of previous studies, however, have reported that concomitant enzyme-inducing AEDs did not affect treatment response, ${ }^{13,14)}$ which is consistent with our results. Younger age at diagnosis of epilepsy is one of the strongest predictors of intractability on univariate analysis. ${ }^{15)}$ As age at epilepsy onset was significantly younger in responders, our result suggests that perampanel offers a treatment option for refractory epilepsy in children as in adults.

The main limitations of the current study were the small patient population and the duration of follow-up. Even with the limitations, the difference from previous pediatric studies on perampanel treatment is that our study only includes children under 12 years of age. Further prospective large-scale studies in young children can possibly help lower the proportion of patients with refractory epilepsy.

\section{Conflicts of interest}

No potential conflict of interest relevant to this article was reported.

\section{References}

1. Brodie MJ. Antiepileptic drug therapy the story so far. Seizure 2010; 19:650-5.

2. Löscher W, Schmidt D. Modern antiepileptic drug development has failed to deliver: ways out of the current dilemma. Epilepsia 2011; 52:657-78.

3. Rudzinski LA, Vélez-Ruiz NJ, Gedzelman ER, Mauricio EA, Shih JJ, Karakis I. New antiepileptic drugs: focus on ezogabine, clobazam, and perampanel. J Investig Med 2016;64:1087-101.

4. Plosker GL. Perampanel: as adjunctive therapy in patients with partial-onset seizures. CNS Drugs 2012;26:1085-96.

5. Shih JJ, Tatum WO, Rudzinski LA. New drug classes for the treatment of partial onset epilepsy: focus on perampanel. Ther Clin Risk Manag 2013;9:285-93.

6. Gidal BE, Laurenza A, Hussein Z, Yang H, Fain R, Edelstein J, et al. Perampanel efficacy and tolerability with enzyme-inducing AEDs in patients with epilepsy. Neurology 2015;84:1972-80.

7. De Liso P, Moavero R, Coppola G, Curatolo P, Cusmai R, De Sarro G, et al. Current role of perampanel in pediatric epilepsy. Ital J Pediatr 2017;43:51.

8. Swiderska N, Tan HJ, Rajai A, Silwal A, Desurkar A, Martland T. Effectiveness and tolerability of Perampanel in children, adolescents 
and young adults with refractory epilepsy: a UK national multicentre study. Seizure 2017;52:63-70.

9. Falco-Walter JJ, Scheffer IE, Fisher RS. The new definition and classification of seizures and epilepsy. Epilepsy Res 2018;139:73-9.

10. Biró A, Stephani U, Tarallo T, Bast T, Schlachter K, Fleger M, et al. Effectiveness and tolerability of perampanel in children and adolescents with refractory epilepsies: first experiences. Neuropediatrics 2015;46:110-6.

11. De Liso P, Vigevano F, Specchio N, De Palma L, Bonanni P, Osanni E, et al. Effectiveness and tolerability of perampanel in children and adolescents with refractory epilepsies-An Italian observational multicenter study. Epilepsy Res 2016;127:93-100.

12. Heyman E, Lahat E, Levin N, Epstein O, Lazinger M, Berkovitch M, et al. Tolerability and efficacy of perampanel in children with refractory epilepsy. Dev Med Child Neurol 2017;59:441-4.

13. Gidal BE, Ferry J, Majid O, Hussein Z. Concentration-effect relationships with perampanel in patients with pharmacoresistant partialonset seizures. Epilepsia 2013;54:1490-7.

14. Kwan P, Brodie MJ, Laurenza A, FitzGibbon H, Gidal BE. Analysis of pooled phase III trials of adjunctive perampanel for epilepsy: impact of mechanism of action and pharmacokinetics on clinical outcomes. Epilepsy Res 2015;117:117-24.

15. Wirrell E, Wong-Kisiel L, Mandrekar J, Nickels K. Predictors and course of medically intractable epilepsy in young children presenting before 36 months of age: a retrospective, population-based study. Epilepsia 2012;53:1563-9. 